\title{
A IMPOSIÇÃO DA PARENTALIDADE SOCIOAFETIVA SOB O PRISMA DA AUTONOMIA DA VONTADE: REVISITAÇÃO DOS PRESSUPOSTOS DE RECOGNIÇÃO DO VÍNCULO PARENTAL SOCIOLÓGICO
}

\author{
IMPOSITION OF SOCIALAFFECTIVE PARENTALITY THROUGH THE \\ PERSPECTIVE OF THE AUTONOMY OF THE WILL: REVIEW OF THE \\ PRESUPPOSITIONS OF RECOGNITION OF SOCIOLOGIC PARENTAL BOND
}

\begin{abstract}
${ }^{1}$ Silmara Domingues Araújo Amarilla
\section{RESUMO}

O trabalho traz como tema a injunção do locus parental socioafetivo e os riscos inerentes à dissociação da paternidade/maternidade sociológica da livre manifestação de vontade. Aborda a compreensão da ambiência familiar sob o paradigma da afetividade e a parentalidade enquanto resultado do desejo pela progenitura. O estudo reflete sobre os pressupostos de conformação da relação parental socioafetiva sob a premissa de que seus vínculos surgem a partir de um processo sincrônico de trocas afetivas e construção identitária, demonstrando que a parentalização reclama espontânea assunção dos papéis parentais, revelando-se inautêntico o liame apartado da autonomia que anima a família na contemporaneidade.
\end{abstract}

Palavras-chave: Família, Parentalidade, Afeto e autonomia da vontade

\begin{abstract}
The work focuses the injunction of the parental socioaffective locus and the risks of its dissociation from the free manifestation of will. Analyses the comprehension of the family environment under the affectivity paradigm and the parentality as a result of the desire for progeniture. Also proposes a scanner of the presupposition of the socioaffective parental relationship under the premise that such bonds arise from a synchronic process of affective exchanges and identitary constitution, demonstrating that the parentalization requires spontaneous acceptance of parental roles, revealing the inauthenticity of the parental bond separated from the autonomy which inspires the contemporary family frame.
\end{abstract}

Keywords: Family, Parentality, Affection and autonomy of the will

\section{CONSIDERAÇÕES INICIAIS}

${ }^{1}$ Doutoranda em Direito pela Pontifícia Universidade Católica de São Paulo - PUC-SP, São Paulo, SP, Brasil. Sócia do escritório Newley, Romanowski, Araújo \& Guerra Advogados Associados.E-mail:

silmaraaraujo@terra.com.br. 
Ao longo da última década habituaram-se os trabalhos acadêmicos a enfrentar o tema do reconhecimento da parentalidade socioafetiva a partir da configuração de um particular status social e familiar, denominado pela construção doutrinária e pretoriana de "posse do estado de filho". Desse modo, consagrou-se o entendimento segundo o qual o reconhecimento da paternidade/maternidade socioafetiva reclama, para sua formatação, a coexistência de três pressupostos, quais sejam nominatio (compartilhamento do patronímico de família), tractatio (tratamento afetivo reciprocamente dispensado por aqueles que se alojam na condição paterna, materna e filial) e reputatio (notoriedade do estado vincular), sendo absolutamente irrelevante qualquer ponderação biológica para a aferição desse modelo familiar.

Diante da (benquista) superação dos arquétipos familiares modernos - que outrora colhiam fundamento num modelo matrimonializado, patricarcal, hierarquizado e patrimonialista -, com a repersonalização e funcionalização dos laços parentais e superação da ideia de um evento biológico como ato fundante da condição paterno/materno-filial, instaurou-se um ambiente propício para recognição do vínculo de parentesco concebido no afeto e nele legitimado, migrando a família, enfim, de instituição voltada à perpetuação da linhagem genética para ambiente facilitador do desenvolvimento biopsicossocial de seus integrantes.

A desbiologização dos vínculos parentais permitiu, portanto, a apreensão da noção do "estado de filiação" e, consequentemente, a legitimação da multiplicidade de origens para o parentesco, promovendo, no campo do Direito de Família, uma verdadeira reconciliação do pensamento com a realidade - ou seja, a restauração da sintonia entre o tratamento jurídico dispensado ao tema e seu estado vivente. Nesse diapasão, reconheceu-se finalmente a socioafetividade enquanto fonte de parentesco (art. 227, § 6º Constituição Federal de 1988; art. 1593, Código Civil de 2002), numa exaltação da família contemporânea funcionalizada.

Dentro desse panorama, a perfilhação sociológica perfectibilizada mediante espontânea lavratura de assentos de nascimentos apartados de qualquer liame biológico, passou a receber novo tratamento jurídico - mais humanizado e coerente com os preceitos e princípios constitucionais que enaltecem a dignidade da pessoa humana, a capacidade de autodeterminação de homens e mulheres no que concerne ao seu status 
pessoal e, sobretudo, a primazia dos melhores interesses de crianças e adolescentes. Estes registros civis, longe de atentarem contra a boa-fé ou merecerem a pecha de falsidade, traduzem (quando espontaneamente promovidos por aqueles que não compartilham com o infante qualquer ancestralidade genética) a verdade vincular sociológica, materializando autêntico desejo de perfilhação.

O empoderamento do afeto enquanto paradigma da parentalidade contemporânea deflagrou inúmeras repercussões no cenário jurídico voltado à apuração e recognição dos vínculos familiares, agora não apenas alicerçados na ascendência genética, mas também consolidados na posse do estado de filiação. Nessa toada, os operadores do direito vêm se deparando, cada vez mais, com ações de investigação da paternidade/maternidade socioafetiva, arguições de existência de parentalidade socioafetiva enquanto fato impeditivo à constituição de vínculo parental de lastro biológico, pretensões voltadas ao reconhecimento de dupla paternidade ou maternidade (fundadas na mesma ou em diversas origens), pedidos de conformação de pluriparentalidade decorrentes das relações de madrastio e padrastio, dentre outras situações.

Diante da guinada paradigmática deflagrada com a promulgação da Carta Federal de 1988 e de toda legislação infraconstitucional que se seguiu, sedia-se o Direito de Família num momento de crucial reflexão acerca dos pressupostos de conformação da parentalidade socioafetiva, particularmente diante de uma eventual disritmia entre o "querer ser pai" (ou mãe) e o "querer ser filho". A compreensão de que o liame parental possui natureza bifronte, que o estado de filiação contempla um conteúdo relacional e que o projeto parental demanda livre engajamento constituirá instrumento-padrão do qual o presente estudo lançará mão para analisar os pressupostos necessários à concreção do vínculo parental fundado na socioafetividade e a impossibilidade de coerção a este especial estado vincular.

\section{OS VÍNCULOS PARENTAIS CONSAGRAdOS NO AFETO E A REFORMATAÇÃO DA PARENTALIDADE A PARTIR DE SEU VIÉS SOCIOLÓGICO}

Como prólogo ao desenvolvimento do tema central algumas ponderações acerca da afetividade enquanto paradigma para a aferição dos vínculos parentais se impõem.Destaca-se inicialmente a importância da apropriação do Direito de 
Família enquanto processo contínuo de edificação dos institutos que lhe são pertinentes, desenvolvendo-se dinamogenicamente mediante perene revisitação de seus conceitos, oxigenação de seus pressupostos de validação e adequação à realidade social ${ }^{1}$.

Necessário, destarte, estabelecer como premissa maior a noção de que a parentalidade consubstancia um fenômeno de ordem social e uma construção psíquica, não guardando qualquer adstrição com o evento biológico da concepção, tampouco com o compartilhamento de dados genéticos. A parentalidade - valendo-se da abordagem lacaniana - diz respeito a uma estrutura anímica na qual cada membro ocupa uma posição, desempenha um papel e assume uma função, existindo, por conseguinte, o lugar do pai, o lugar da mãe e o lugar do filho, sem que, unindo-os, haja necessariamente qualquer traço de consanguinidade ${ }^{2}$.

Foi lenta e árdua a marcha que conduziu o conceito tradicional de família calcado na matrimonialidade, na gestão superlativa do homem e na relevância da perpetuação do patrimônio dentro do núcleo familiar instituído e validado pelo casamento $^{3}$ - ao reconhecimento do pluralismo no ambiente familiar, não apenas quanto à multiplicidade de origens vinculares, mas também quanto à sua estrutura organizacional e gestão.

É sabido que o Código Civil de 1916, embora tenha colhido inspiração no ideário iluminista encampado pelo Code, sob o mote da igualdade, liberdade e fraternidade, findou por consagrar normas de cunho flagrantemente segregatório, individualista e patrimonialista, persistindo, a exemplo das codificações que o antecederam, na ideia de submissão da legitimidade da família ao casamento civil, de proeminência da figura masculina na chefia e gestão familiar e de tratamento

\footnotetext{
${ }^{1}$ Significa dizer que o quadro de referências do qual lança mão o Direito de Família para assegurar seu continuum "lega posse do passado para o futuro" (ARENDT, 1979, p. 31), seja no sentido de validar o modelo vigente, seja no sentido de revisitá-lo e conformá-lo à realidade.

${ }^{2}$ Conquanto discorra particularmente acerca da paternidade, Rodrigo da Cunha Pereira desenvolve a teoria lacaniana para sustentar que pai é aquele que ama, cuida, ampara e educa; nem sempre aquele que gera. Tal locus parental pode, partindo dessa noção, ser ocupado pelo próprio genitor, pelo marido da mãe, pelo amante oficial, pelo avô ou por qualquer outra pessoa que exerça a paternagem (PEREIRA, 2003, p. 121).

${ }^{3}$ Falando ainda sob a égide da Constituição pretérita, Orlando Gomes compõe o conceito de família a partir de três critérios: o sucessorial, pelo qual "a família constitui o grupo formado pelos cônjuges e parentes próprios", em que "uns sucedem os outros, no pressuposto de que se acham unidos pelo vínculo familiar"; o da legitimidade, consubstanciando-se a família em um "grupo composto pelo marido, mulher e filhos, fundado na legitimidade", sem se esquecer da família natural; e o da autoridade, caracterizandose a família como um "pequeno grupo social de pessoas unidas pelos laços de parentesco e vida comum", subordinadas à mesma direção (GOMES, 1983, p. 30). Ainda no que concerne ao conceito tradicional de família, define-a Clóvis Beviláqua como "um conjunto de pessoas ligadas pelo vínculo da consanguinidade, cuja eficácia se estende ora mais larga, ora mais restritamente, segundo as várias legislações. Outras vezes, porém, designa-se, por família, somente os cônjuges e a respectiva progênie" (BEVILÁQUA, 1976, p.16).
} 
diferenciado dos filhos havidos sob o manto do matrimônio e fora dele. No cenário jurídico instaurado pelo Código de Beviláqua foram sumariamente ignorados quaisquer formatos familiares que não observassem o perfil por ele então delineado, conferindo referido Diploma preponderância à família enquanto instituição e bunker patrimonial.

A biografia da família brasileira deve render homenagens à legislação esparsa que, após a promulgação do Código Civil de 1916, ainda que por vezes de maneira tímida, parcimoniosa e descompassada com as expectativas sociais, logrou conquistas no campo da equalização dos direitos dos filhos, independentemente de sua origem ${ }^{4}$, na minimização da matrimonialidade enquanto pressuposto de legitimação para família e na superação das desigualdades vivenciadas nas relações conjugais, convivenciais e parentais. Também não se deve olvidar a relevância da Carta Federal de 1934 na contemplação da família como tema constitucional ${ }^{5}$, sob especial proteção do Estado.

Em que pese a notabilização dos referidos diplomas, não há como ignorar o papel essencial desempenhado pela Constituição de 1988 na mudança paradigmática do conceito de família, finalmente pondo termo no tratamento desigual dispensado à filiação (art. 227, $\S 6^{\circ}$ ) e na disparidade entre homens e mulheres no exercício dos poderes de gestão dentro da estrutura conjugal (art. 226, $\S 5^{\circ}$ ), devotando destacada proteção às entidades familiares, inclusive (mas não exclusivamente) em sua conformação monoparental e convivencial ( $\operatorname{art} .226, \S \S 3^{\circ}$ e $4^{\circ}$ ).

A Carta Federal de 1988 pode, portanto, ser qualificada como elemento catalisador da mudança paradigmática do conceito de família, selando um modelo igualitário, associativo, participativo, calcado na solidariedade e legitimado no afeto ${ }^{6}$.

4 tei n. ${ }^{\circ} 883 / 49$ (2ilhos ilegítimos); Lei n. ${ }^{\circ}$ 4.121/62 (Estatuto da mulher casada); Emenda Constitucional n. ${ }^{\circ}$ 9/77; Lei n. ${ }^{\circ}$ 6.515/77 (Lei do Divórcio), dentre outras.

5 A Constituição Federal de 1934 atribuiu efeitos civis ao casamento religioso e, de maneira inédita, inseriu a dissolução da sociedade conjugal como matéria constitucional, conservando a indissolubilidade do casamento e dispondo sobre o desquite. Ainda dedicou especial proteção do Estado à família (Título V, Capítulo I), assim considerada aquela constituída pelo casamento indissolúvel (art. 144, CF/1934). A Carta de 1934 também tratou da possibilidade de reconhecimento dos filhos naturais (ou seja, aqueles havidos fora do casamento) e seu direito à herança (art. 147, CF/1934).

${ }^{6}$ Conquanto a Carta de 1988 não tenha feito referência expressa ao afeto ou à afetividade, concebe-se da leitura sistematizada de seus preceitos e, sobretudo, dos princípios ali exaltados, sua consagração enquanto princípio constitucional e elemento legitimador da família contemporânea. Tal leitura se impõe a partir da conjugação do princípio que assegura, com prioridade, a convivência familiar a crianças e adolescentes, sem qualquer condicionante biológica (CF/1988, art. 227), do tratamento isonômico dispensado à prole, independentemente de sua origem $\left(\mathrm{CF} / 1988\right.$, art. $\left.227, \S 6^{\circ}\right)$, da tutela da adoção, enquanto escolha afetiva, em paridade de direitos, deveres e garantias $\left(\mathrm{CF} / 1988\right.$, art. 227 , $\S 5^{\circ}$ e $\left.6^{\circ}\right)$ e a proteção dispensada à família monoparental, integrada por qualquer dos pais e sua prole $(\mathrm{CF} / 1988$, art. 
Sua relevância, a propósito, transcende a abordagem pontual de temas afins à estrutura familiar e parental; seu maior mérito consiste, efetivamente, na oxigenação de todo sistema normativo subjacente com a carga axiológica emanada de seus princípios norteadores:

\begin{abstract}
A Constituição de 1988, centro reunificador do direito privado, disperso diante da proliferação da legislação especial e da perda de centralidade do Código Civil, consagrou, em definitivo, uma nova tábua de valores no ordenamento brasileiro. O pano de fundo dos polêmicos dispositivos em matéria de família pode ser identificado na alteração do papel atribuído às entidades familiares e, sobretudo, na transformação do conceito de unidade familiar que sempre esteve na base do sistema. A reflexão sobre o impacto dessa ruptura axiológica torna-se indispensável para que se compreenda o sentido hermenêutico a ser atribuído às sucessivas leis especiais, e, especialmente, ao Código Civil de 2002 no que tange ao direito de família. Verifica-se, do exame dos arts. 226 a 230 da Constituição Federal, que o centro da tutela constitucional se desloca do casamento para as relações familiares dele (mas não unicamente dele) decorrentes; e que a milenar proteção da família como instituição, unidade de produção e reprodução dos valores culturais, éticos, religiosos e econômicos, dá lugar à tutela essencialmente funcionalizada à dignidade de seus membros, em particular no que concerne ao desenvolvimento da personalidade dos filhos (TEPEDINO, 2008, p. 420-421).
\end{abstract}

Sob os influxos da nova tábua de valores cunhada pela Carta de 1988, a produção legislativa recobrou forças no sentido de expandir as conquistas até então alcançadas no terreno da parentalidade. Nessa toada, merece especial destaque o Estatuto da Criança e do Adolescente (Lei n. ${ }^{\circ}$ 8.069, de 13 de julho de 1990), haja vista o reconhecimento explícito do dever da família em assegurar à criança e adolescente a vida, a saúde, a alimentação, educação, esporte, lazer, profissionalização, cultura, dignidade, respeito, liberdade e convivência familiar e comunitária (art. $4^{\circ}$ ), bem como pela renovada consagração da igualdade de direitos da filiação, independentemente de sua origem (art. 20).

Após longo percurso legislativo e inúmeras alterações em seu texto primitivo o que, para muitos, depauperou a visão originariamente timbrada por Miguel Reale -, sobreveio, em agosto de 2001, o novo Código Civil, inovando (se cotejado com o diploma precedente) no terreno da parentalidade ao reconhecer a existência de múltiplas

226, $\S 4^{\circ}$ ), emergindo da sinergia estabelecida entre estes preceitos o princípio constitucional da afetividade (LÔBO, 2009, p. 453-472). 
origens de parentesco ${ }^{7}$ e a igualdade de direitos da filiação, fundada ou não na consanguinidade ${ }^{8}$.

Curial registrar, neste passo, que a família e os institutos que lhe são caros não decorrem das normas, tampouco do Estado ou da Igreja (VILLELA, 1999); a família, na verdade, precede qualquer regramento que lhe faça referência ${ }^{9}$. Quer isso dizer que as mudanças ocorridas no âmago da sociedade e o modo pelo qual pais, mães e filhos vivenciam seus vínculos consubstanciam a força motriz do tratamento jurídico dispensado ao tema, guiando a mutação de um modelo para outro.

Tomando por empréstimo as lições de Thomas Kuhn, o processo de transição paradigmática instaura-se com a compreensão de que determinado conjunto de compromissos $^{10}$ carece da aptidão necessária para responder adequadamente os questionamentos sociais, deflagrando, assim, uma crise no conjunto de instrumentos tradicionalmente aceitos como padrão, com o consequente colapso de um modelo, até então aceito, em prol de outro, distinto e mais consentâneo com a realidade (KUHN, 2009).

Portanto, a concepção e consolidação de um modelo paradigmático reclamam o entendimento de que a aplicação de um determinado conjunto de regras produz uma quantidade de anomalias tal - tanto do ponto de vista quantitativo, quanto do ponto de vista qualitativo, levando em consideração, neste último aspecto, a relevância do eixo de questionamentos e ponderações envolvidos - que sua superação é o único caminho viável a fim de remediar a arritmia entre a teoria e a práxis, sanando-se a crise. Ou seja, “o fracasso das regras existentes é o prelúdio para a busca de novas regras" (KUHN, 2009, p. 95), reformulando-se o pensamento que até então se encontrava apartado da realidade no sentido de restaurar-lhe significação (ARENDT, 1979, p. 32).

Particularmente no que concerne aos vínculos familiares e parentais o que se observou foi que o tratamento jurídico dispensado ao tema - ou seja, o conjunto de

\footnotetext{
${ }^{7}$ Código Civil de 2002. Lei n. ${ }^{\text {o }} 10.406$, de 10 de janeiro de 2002, art. 1593: O parentesco é natural ou civil, conforme resulte de consanguinidade ou de outra origem.

${ }^{8}$ Código Civil de 2002. Lei n. ${ }^{\circ}$ 10.406, de 10 de janeiro de 2002, art. 1596: Os filhos havidos ou não da relação de casamento, ou por adoção, terão os mesmos direitos e qualificações, proibidas quaisquer designações discriminatórias relativas à filiação.

9 A partir dessa perspectiva, crê-se que o movimento mutacional no arquétipo familiar ocorreu não propriamente no âmago da família contemporânea - há muito tempo já modificada em sua estrutura, dinâmica, gestão e vocação -, mas sim em sua ordem de recognição. Ou seja, o pensamento consagrado pela Constituição Federal de 1988 nada mais fez que legitimar o modelo de família e parentalidade já vivenciados pela sociedade, tutelando-lhe especial proteção (AMARILLA, 2014, p.65).

10 Regras endossadas pela comunidade científica na resolução de um determinado plexo de questionamentos.
} 
instrumentos-padrão disponibilizados pelo sistema para a solução dos questionamentos emergentes da comunidade - não mais afiançava uma resposta adequada às perplexidades sociais, gerando a progressiva ampliação de uma zona de penumbra para a qual eram lançadas todas aquelas situações à margem do regramento (pensamento) tradicionalmente aceito. Ou seja, quanto mais encorpado esse território cinzento, mais debilitada a legitimidade do modelo paradigmático adotado e recrudescida a cisão daquilo que se reputava apropriado e a realidade.

Desse modo, o sistema jurídico-normativo dedicado à família e à parentalidade foi maturado ao longo das últimas décadas pelas profundas mudanças vivenciadas pela sociedade, tais como a inserção da mulher no mercado de trabalho (donde sobreveio sua emancipação econômica, com consequências diretas na repaginação das funções domésticas e no exercício da gestão familiar), a emancipação sexual feminina (com a disseminação dos métodos contraceptivos e, por conseguinte, a consolidação do livre planejamento familiar) e o aumento do grau de escolaridade de crianças e jovens (com a sobrevalorização do ser humano nessa especial fase de seu desenvolvimento), guinandose o modelo familiar e parental tradicionalmente aceito, com raízes fincadas no patriarcado e na visão hierarquizada da parentalidade, para uma nova estrutura e, sobretudo, para uma nova função.

Ponderando acerca da relevância dos fatos sociais que notabilizaram a redefinição do perfil familiar, com especial enfoque em sua aptidão transformadora, Maria Berenice Dias e Rodrigo da Cunha Pereira asseveram:

\footnotetext{
A partir da segunda metade do século XX, está-se vivendo um importante processo de transformação, determinado - entre outros fatores - pela quebra da ideologia patriarcal, impulsionada pela revolução feminista. À evolução do conhecimento científico, somaram-se o fenômeno da globalização, o declínio do patriarcalismo e a redivisão sexual do trabalho, a ensejar uma profunda mudança na própria família.

A travessia para o novo milênio transporta valores totalmente indiferentes, mas traz como valor maior uma conquista: a família não é mais essencialmente um núcleo econômico e de reprodução, onde sempre esteve instalada a suposta superioridade masculina. Passou a ser - muito mais que isso - o espaço para o desenvolvimento do companheirismo, do amor e, acima de tudo, o núcleo formador da pessoa e elemento fundante do próprio sujeito (DIAS; PEREIRA, 2005, Prefácio, p. viii).
}

Pode-se afirmar, por conseguinte, que o reconhecimento do pluralismo na conformação das entidades familiares e uma visão mais democrática das relações parentais contemporâneas têm suas origens na repersonalização dos vínculos nutridos 
nesse especial núcleo de convívio, na dissociação da ancestralidade biológica e na alforria de qualquer vocação patrimonial.

Nessa senda, partindo de uma hermenêutica construtivista do Texto Constitucional, segundo a qual deve se conferir primazia à dignidade da pessoa humana, à liberdade, à capacidade de autodeterminação de homens e mulheres na edificação de seu projeto pessoal de felicidade, à igualdade, ao pluralismo e à consagração da família enquanto ambiente propício para o integral desenvolvimento de crianças e adolescentes, o sistema jurídico-normativo reconhece que toda pessoa é titular do direito fundamental de constituir um núcleo familiar e conceber laços de parentalidade, independentemente de qualquer layout previamente definido, sendo absolutamente irrelevante, nessa empreitada, a conjunção de pares (biparentalidade), a diferença de gêneros (heteroparentalidade), ou, ainda, o compartilhamento de dados biológicos com a prole. O que permeia e qualifica tais laços, portanto, é seu conteúdo afetual e cooperativo; funcionalizado, enfim.

\section{O DESEJO PELA PROGENITURA E A MATERIALIZAÇÃO DO PROCESSO DE PARENTALIZAÇÃO: A RELEVÂNCIA DA VONTADE NA CONFORMAÇÃO DOS VÍNCULOS PARENTAIS SOCIOAFETIVOS}

Deixando a parentalidade de colher legitimidade no matrimônio, alforriando-se do sexo e da vocação de perpetuidade da linhagem biológica, bem como do mandato transgeracional do patrimônio, os vínculos gestados e nutridos por pais, mães e filhos passaram a encontrar arrimo noutro valor diretivo - o afeto -, prestigiando-se, então, a vontade de engajamento no projeto parental como elemento de exteriorização da liberdade e da capacidade de autorregramento no campo da progenitura.

Já tendo sido lançadas anteriormente três premissas fundantes na concepção do tema aqui versado, quais sejam (i) a transposição da vocação outrora infundida à família (voltada inicialmente à perpetuação da linhagem biológica e concentração do patrimônio dentro do núcleo fundado pelo matrimônio), (ii) a superação de qualquer visão dicotômica e antagonista de perfis familiares (mediante a consagração de um modelo plural e inclusivo), e (iii) a dissociação dos vínculos parentais de qualquer determinismo genético, surge, então, uma quarta vertente igualmente relevante: a 
convalidação da paternidade/maternidade-filiação na socioafetividade, lastreada, por sua vez, na livre e espontânea associação ao projeto parental.

Partindo do pressuposto que a perfilhação socioafetiva demanda um conjunto de arranjos intersubjetivos voltados à concepção não biológica, mas psíquica, bem como à introjeção da função, do papel e do status de pai ou mãe, indaga-se como seria possível - sem a afronta indelével à autonomia de vontade - imputar a paternidade ou a maternidade a alguém que não deseja vivenciar esta condição.

A parentalidade socioafetiva (em sua vertente puramente sociológica) é resultado da vontade e da espontaneidade daquele que, mesmo ciente da ausência de vínculos biológicos, manifesta de modo concreto o desejo de perfilhar outrem, assumindo a função parental e todos os direitos e deveres inerentes a este particular status pessoal, qualificado pela vivência da paternagem e maternagem. Nota-se, portanto, a partir dessa concepção, que a autonomia da vontade desempenha papel central na conformação da parentalidade socioafetiva, fundando-se na livre e consciente instauração do processo de parentalização.

Qualquer trabalho de investigação da parentalidadade enquanto estrutura psíquica reclama a consulta aos estudos desenvolvidos pelo psiquiatra infantil e psicanalista francês Serge Lebovici, professor emérito da Faculdade de Medicina da Universidade de Paris e pesquisador do processo de "tornar-se pai ou mãe". A partir de suas vivências e observações clínicas quanto às dificuldades experimentadas nas relações paterno/materno-filiais, Lebovici pôde compreender que o conceito de parentalidade encontra-se apartado de qualquer evento biológico, não sendo propriamente um fenômeno, mas sim um processo. Partindo desse raciocínio, a parentalidade não estaria circunscrita às divisas biológicas, tampouco despontaria subitamente (LEBOVICI, 2004a).

Fazendo referência aos estudos desenvolvidos por Lebovici, Leticia SolisPonton explana que o processo de parentalização se caracterizaria pelo sincronismo e reciprocidade, donde concluir que "o bebê faz seus pais" (SOLIS-PONTON, 2004, p.32), ou seja, o conjunto de aptidões (ou competências) da prole parentaliza seus pais simultaneamente à sua própria parentalização por estes. Esta assertiva ganha importância não apenas no reconhecimento do papel da criança enquanto sujeito ativo na construção da parentalidade, mas também na percepção do dinamismo que qualifica as interações de pais, mães e filhos, interações estas que demandam reciprocidade e encontram-se subordinadas ao fator tempo-espaço de convívio.Afirma-se, com isso, que 
a parentalidade consiste numa construção - ou seja, é iniciada e desenvolvida continuamente -, materializando-se mediante a avocação da condição de pai (do "tornar-se pai"), mãe (do "tornar-se mãe") e filho ("tornar-se filho"), assumindo cada qual um papel e uma função dentro da ambiência familiar, parentalizando-se mútua e reciprocamente com os aportes afetivos e vivências cotidianas.

Ainda no que concerne à edificação da parentalidade, deve-se ter em mente que esse processo é desenvolvido sobre três vieses fundamentais e indissociáveis do livre engajamento: a experiência, o exercício e a prática (HOUZEL, 2004). A experiência da parentalidade diz respeito à vivência subjetiva, consciente e inconsciente, do "vir a ser pai" e "vir a ser mãe", o que se inaugura com o desejo pela progenitura, desenvolvendose pelo processo de parentalização. $O$ exercício da parentalidade concerne à transcendência da individualidade daquele que assume o posto de pai ou mãe, com as renúncias e abdicações necessárias para o desempenho dos direitos e deveres que decorrem desse especial laço associativo, com a tutela de um espaço familiar, social, psíquico e afetivo à prole, vocacionado ao desenvolvimento de sua personalidade, potencialidades e competências. A prática da parentalidade, por derradeiro, dialoga com a execução cotidiana das tarefas de apoio de pais e mães junto à sua prole, mediante o aporte dos cuidados indispensáveis ao seu crescimento, rumo à autonomia. Fácil perceber que estes três eixos não se encontram compartimentados, guardando entre si várias interfaces e conexões; entremeando-os estão a vontade, a liberdade e a autonomia de fundar um novo núcleo familiar, dignificado pelo afeto.

Nesse contexto e retomando o pensamento lançado anteriormente, tem-se que a parentalidade não se instaura de modo instantâneo com a descoberta da concepção, com a superveniência do parto ou a partir de qualquer outro fenômeno biológico; a parentalidade principia no desejo pela progenitura, consolidando-se progressivamente, enquanto edificação psíquica, pelo processo de parentalização, "qualificado pela migração de seus partícipes da condição de adultos para a condição de pais e mães, com as abdicações narcísicas necessárias à reestruturação das malhas de pertinência e prioridades" (AMARILLA, 2014, p.33).

De tudo o que se expôs até o presente instante, salta aos olhos e inviabilidade (não apenas jurídica, mas também fática) da imposição judicial do vínculo parental socioafetivo, padecendo de patente inexequibilidade a injunção da experiência do “tornar-se pai ou mãe". De fato, os intercâmbios afetivos e simbólicos demandados 
peloprocesso de parentalização apenas poderão ser realizados espontaneamente; o deslocamento de homens e mulheres que almejam engajar-se no projeto parental reclama a transposição de sua própria individualidade, exigindo adaptações internas que somente poderão germinar no terreno fértil da liberdade e da autonomia.

\section{A VONTADE ENQUANTO PRESSUPOSTO PARA A CONFIGURAÇÃO DO VÍNCULO DE PARENTALIDADE SOCIOAFETIVA: A INEXEQUIBILIDADE DA INJUNÇÃO VINCULAR SOCIOAFETIVA DISSOCIADA DO ANIMUS PARENTAL}

Infere-se das ponderações trazidas a lume que a parentalidade socioafetiva encontra-se alicerçada não exclusivamente no compartilhamento de um apelido de família, no tratamento afetuoso (ainda que de timbre familiar) e na averiguação social; a condição paterno/materno-filial também reclama a livre exteriorização da vontade de ser pai ou mãe, em suma, de estabelecer, com relação a outrem, um vínculo de parentalidade.

Assim, ao lado da "posse do estado de filho" - ante o qual existe, em simetria, uma "posse do estado de pai" e uma "posse do estado de mãe" -, surge como pressuposto necessário ao reconhecimento do vínculo parental socioafetivo o unívoco propósito de perfilhação; a vontade de alguém no sentido de ver-se juridicamente investido no status parental:

[...] Para além da posse de estado, porém, entende-se que a filiação socioafetiva requer outro pressuposto principal: a unívoca intenção daquela que age como se genitor (a) fosse de se ver juridicamente instituído pai ou mãe. Assim porque nem todo aquele que trata alguém como se filho fosse quer torná-lo juridicamente seu filho. Afinal, a constituição da qualidade de pai ou mãe enseja, dentre outros efeitos, uma série de deveres jurídicos que, se não cumpridos espontaneamente, comportam, até mesmo execução compulsória. Logo, é preciso ter cautela no estabelecimento deste parentesco socioafetivo, sob pena de - uma vez desmerecida a real vontade do pretenso ascendente - lhe suprimir a essência, qual seja a edificação espontânea e pura. Essa manifestação inequívoca, então, há de ser expressa ou claramente dedutível de qualquer meio de prova idôneo, particular ou público, como o testamento, por exemplo. Na dúvida, fica prejudicada a caracterização do vínculo paterno ou materno-filial socioafetivo (ALMEIDA; RODRIGUES JÚNIOR, 2010, p.390-391). 
Não por outra razão a construção doutrinária e pretoriana desse particular vínculo de parentesco tomou como ponto de partida a intitulada "adoção à brasileira", circunstância que decorre da declaração "falsa"11 e consciente da paternidade ou maternidade de alguém (comumente infante), sem lastro biológico subjacente. $\mathrm{O}$ assento de nascimento lavrado por livre iniciativa e manifestação consciente de vontade daquele que não é procriador genético consubstancia ato inaugural de perfilhação, sendo idôneo o registro promovido nestes moldes porquanto "conciliado com o fato jurídico que lhe deu origem" (VILLELA, 1999a, p. 138-139).

Percebe-se que a parentalidade socioafetiva encontra-se subordinada à manifestação de vontade daquele que perfilha, seja no assento de nascimento, seja por qualquer outro instrumento, público ou particular, idôneo à exteriorização inequívoca de sua intenção. A perfilhação sociológica - ou seja, a assunção da maternidade ou paternidade de alguém com quem não se possui identidade genética e que não foi adotado formalmente -, depende, portanto, de um ato voluntário e espontâneo de assunção da condição parental, seguindo-se, obviamente, a convivência duradoura e qualificada pelos requisitos do nominatio $^{12}$ tractatio $^{13}$ e reputatio $^{14}$.

O que se deve entender é que ao longo de uma vida é possível estabelecer com outras pessoas, que não pai e mãe, relações de afeto, carinho e respeito, sem que, no entanto, destes laços decorra qualquer vínculo parental. Assim são as ligações lastreadas nas amizades, no sentimento de proteção e auxílio próprio dos padrinhos e madrinhas e no auxílio pautado pelo elevado espírito de solidariedade para com o próximo. Atribuir a esses vínculos - espontaneamente geridos para serem o que são, e nada mais - o qualificativo de parentalidade, com repercussões registrais e patrimoniais, não apenas carece de previsão jurídica específica, como também vulnera a autonomia, vontade e liberdade daqueles que pretendem amar e auxiliar sem ser ou se tornar, para tanto, pais ou mães.

Significa dizer que o simples fato de existir entre duas ou mais pessoas o intercâmbio de amor, cuidado e amparo, ainda que exteriorizados de tal modo que, para o observador social, assemelhe-se a uma relação parental, não conduz necessariamente à conformação do vínculo paterno/materno-filial, reclamando-se, para tanto, nas palavras

${ }^{11}$ Discorda-se da imputação de falsidade a esta espécie de declaração, vez que o registro, ultimado nestes moldes, traduz a realidade vincular sociológica, que pode ou não encontrar-se arrimada na ancestralidade biológica daquele ou daquela que avoca a condição de pai ou mãe.

${ }^{12}$ Utilização do patronímico do suposto pai ou suposta mãe. 
${ }^{13}$ Demonstração inequívoca de afeto na condição de pai ou mãe.

14 Notoriedade da relação afetiva, de cunho paterno/maternofilial.do Ministro do Superior Tribunal de Justiça, João

Otávio Noronha, "demonstração da vontade manifesta do 'adotante' de estabelecer laços de parentesco com efeitos patrimoniais", donde inferir que "afetividade não é sinônimo de vontade, que tem de ser manifestada" (BRASIL, 2015).

Mantendo em riste essa ideia, tem-se que o reconhecimento da parentalidade socioafetiva encontra arrimo na necessidade de preservação de uma relação jurídicoparental preexistente e consolidada, instaurada mediante a manifestação de ato voluntário e formal de perfilhação. Portanto, a maternidade ou paternidade dita sociológica não logrará ser infligida à revelia daquele que voluntariamente deixou de assumir este status, impondo a quem quer que seja um projeto de vida que jamais concebeu para si.

Revela-se recomendável a redobrada atenção daqueles que operam com o tema debatido neste estudo no sentido de não ceder à sedução argumentativa de tutela ao princípio da dignidade da pessoa humana como justificativa para a imposição judicial da parentalidade socioafetiva. De fato, pululam ações ditas investigativas de paternidade e maternidade socioafetiva por intermédio das quais se pretende, sob o estandarte da tutela ao referido princípio, a conformação de um vínculo parental que jamais existiu no plano jurídico, lançando-se por vezes mão destas investidas quando já falecido o cobiçado "pai" ou "mãe"; ou, ainda, ansiando-se por uma cumulação imprópria de diversas pessoas nestes postos familiares.

Registre-se de antemão que a multiplicidade parental emanada da dupla maternidade ou paternidade é perfeitamente admissível a partir da leitura otimizada dos princípios constitucionais, dialogando essa possibilidade com a liberdade e autonomia que assistem aos cidadãos na estruturação de um layout familiar individualizado e singularizante. $\mathrm{O}$ que merece particular censura - retomando a assertiva alinhavada no parágrafo anterior - é reduzir a dignidade da pessoa humana e sua destacada proteção constitucional a mero recurso retórico (VILLELA, 2009), no afã de travestir pretensões inspiradas por reles interesses patrimoniais em mecanismos de tutela dos direitos de personalidade.

Calha, neste passo, abordar as repercussões do princípio da liberdade e da autonomia privada no campo da parentalidade, consagrando especial atenção à construção e recognição dos vínculos socioafetivos. 
O princípio constitucional da liberdade e seu imbricamento com a autonomia privada (assim compreendida a capacidade de autodeterminação e autorregramento doindivíduo) espraia seu conteúdo pelo terreno familiar para assegurar a concepção de um modelo de convívio singularizado, ou seja, que melhor atenda aos interesses, convicções e, sobretudo, ao projeto de vida encampado por seus partícipes, salvaguardando-lhes o ordenamento jurídico-constitucional de qualquer tratamento discriminatório. Dizendo de outra maneira, diante da carga axiológica emanada da Carta Federal de 1988, gozam os indivíduos de liberdade e autonomia para elegerem uma estrutura familiar particularizada, sem qualquer submissão à matrimonialidade, à conjugalidade, à heteroparentalidade ou, ainda, aos vínculos biológicos com sua prole.

O que se constata, pois, a partir desse conteúdo valorativo, é uma especial proteção à família - e, consequentemente, à parentalidade - qual seja o seu perfil, num autêntico enaltecimento exaltação do viés pluralista e inclusivo encampado pela Constituição Federal de 1988. Na visão esposada por Guilherme Calmon Nogueira da Gama (2008, p. 75), “o princípio da liberdade, [...], no âmbito das relações familiares, se associa à autonomia privada no segmento da liberdade de escolha, de manutenção e de extinção da entidade familiar".

Aludido princípio guarda, pois, estreita sintonia com a garantia de livre formulação de um projeto parental individualizado, pautado na responsabilidade, na cooperação e na promoção do integral desenvolvimento de seus membros mais vulneráveis.

Ora, se toda família é credora de especial proteção constitucional, independentemente de seu formato, se toda espécie de vínculo parental, fundando ou não na consanguinidade, encontra resguardo legal, se todo cidadão é livre para conceber um projeto de vida que se coadune com suas convicções pessoais, como seria possível a injunção estatal na vontade humana no sentido de constranger quem quer que seja à progenitura que jamais almejou constituir? Como será possível impor à paternidade e maternidade àqueles que não desejaram experimentá-las, exercitá-las e praticá-las, tampouco livre e conscientemente filiaram-se ao processo de parentalização, com o compartilhamento de vivências afetivas, asseguração de referências, transmissão de valores e perpetuação de cultura inerentes a esse particular estado associativo?

Nos termos do que restou assentado previamente neste estudo, a parentalidade diz respeito a um fenômeno psíquico, social e cultural que guarda em seu cerne um 
perfil dialógico e relacional, desenvolvendo-se sincronicamente entre alguém que se investe no estado de paternidade/maternidade e outrem, no estado de filiação:Filiação é conceito relacional; é a relação de parentesco que se estabelece entre duas pessoas, uma das quais é considerada filha da outra (pai ou mãe). O estado de filiação é a qualificação jurídica dessa relação de parentesco, atribuída a alguém, compreendendo um complexo de direitos e deveres reciprocamente considerados. O filho é titular do direito ao estado de filiação, da mesma forma que o pai e a mãe são titulares dos estados de paternidade e de maternidade, em relação a ele (LÔBO, 2004, p. 507-508).

Deve-se, por conseguinte, compreender o "estado de filiação" como espelhamento do "estado parental", havendo entre ambos a mútua disposição de pertencer a determinado núcleo familiar, imbuindo-se cada um dos partícipes de um papel diferenciado.

Em sua dimensão socioafetiva, os postos parentais concebidos à revelia do desejo e da manifestação qualificada de vontade depauperam sua real vocação, esvaziando o significado da paternidade e maternidade enquanto expressão máxima da liberdade na conformação de um projeto de vida singularizado.

Há de se refletir, neste passo, acerca da adulteração da situação jurídica estabelecida nos assentos registrais e consolidada pela convivência familiar duradoura e qualificada, mediante a imputação judicial de um segundo vínculo parental socioafetivo, seja no mesmo locus (ensejando, daí, a conformação de dupla paternidade ou maternidade), seja em locus distinto (com a alteração da monoparentalidade primária).

Tais pretensões, voltadas à alteração de registros de nascimento quanto à ascendência social e comumente cumuladas com pedidos de cunho patrimonial (assistencial ou sucessório), quando formuladas à revelia do almejado "pai" ou "mãe" socioafetivo, conspurcam a essência desse particular vínculo, que só se manifesta como visto - enquanto edificação espontânea.

À tardia reivindicação do vínculo parental socioafetivo deduzida nestes moldes, dissociada de qualquer causa moral legítima e alicerçada na repercussão patrimonial que lhe servirá de corolário, falece qualquer carga afetual, também desservindo à conformação identitária e ao pleno acesso da historicidade pessoal. O que se pretende por intermédio dessas investidas é o reconhecimento de um vínculo parental que jamais foi experimentado, exercitado ou praticado, como se fosse possível conferir primazia a um modelo parental em detrimento do outro, em desrespeito ao princípio constitucional que consagra tratamento igualitário à família, independentemente de seu formato, e à filiação, independentemente de sua origem. 
Se a parentalidade socioafetiva tem por condão oferecer sustentáculo a uma relação jurídico-parental preexistente, constituída mediante ato formal e voluntário de perfilhação, impô-la àquele ou àquela que não deseja assumi-la vulnera, por um lado, a dignidade dos partícipes do núcleo familiar artificialmente concebido, e, por outro, a história de vida fundada pelo registro primitivo, esteada no tempo e num ambiente qualificado de convívio, apequenando a relevância do cuidado, amparo e afeto dedicados pelo ascendente registral primitivo, ao qual coube - nos moldes anteriormente declinados neste estudo - a experiência, o exercício e a prática da parentalidade.

$\mathrm{O}$ fato de se alterar, sob as condições declinadas alhures, um determinado núcleo familiar (já estabilizado do ponto de vista jurídico), mediante a fundação de um novo conjunto vincular, implica na repaginação de um complexo conjunto de tramas intersubjetivas, pautadas na vivência de lealdades, pactos e compromissos. Fazê-lo irrefletidamente, pautando-se na vã e rasteira arguição de proteção aos direitos da personalidade e dignificação da condição humana, longe de engrandecer o instituto da parentalidade socioafetiva, fragiliza-o, esvaziando o conteúdo relacional dos vínculos de paternidade e maternidade, suas interações afetivas, simbólicas e referenciais.

A assunção da parentalidade socioafetiva demanda, pois, engajamento e ajustes psíquicos que só frutificam no terreno da liberdade e autonomia, sendo impossível ao Estado ingerir na vontade humana - sem depreciá-la gravemente - para constranger homens e mulheres à progenitura pela qual jamais ansiaram.

\section{CONCLUSÃO}

As reflexões sobre a parentalidade socioafetiva que ora são trazidas a lume não ostentam uma finalidade estritamente teórica. Têm a confessada ambição de contribuir de maneira objetiva na busca por instrumentos válidos de identificação de vínculos parentais reais, guarnecidos de significado e significância.

A expressa referência aos eixos da parentalidade realça a necessidade de apuração do vínculo em suas múltiplas dimensões, sem olvidar suas características de livre engajamento, reciprocidade e interação.

Se é verdade que a função social da família contemporânea diz respeito à construção de um ambiente facilitador para o desenvolvimento de seus 
integrantes, viabilizando-lhes a constituição identitária e seu próprio processo de humanização, não menos verdade que tal vocação somente poderá prosperar no terreno da liberdade e da autonomia, sem os quais perecerá numa projeção vincular desprovida de qualquer conteúdo simbólico e referencial.

Partindo dessa premissa, conceber coercitivamente um vínculo parental socioafetivo, dissociado do desejo pela progenitura e da livre associação ao processo de parentalização, traduz, por um lado, depreciação da vontade humana quanto à livre concepção do projeto de vida, e, por outro, grave comprometimento da natureza do liame paterno/materno-filial.

Buscando a harmonização dos institutos afins ao Direito de Família com o contínuo fluxo de modificações vivenciadas nas relações sócio-jurídico-culturais, compreender o fenômeno da parentalidade socioafetiva livre de standards morais ou associações ideológicas permite amadurecer um conjunto de ferramentas-padrão voltados à apreensão da real dinâmica de famílias nos seus mais variados formatos, pautados na livre concepção de um projeto personalizado de vida e legitimados no afeto.

Assim, a parentalidade socioafetiva dialoga intimamente com a livre associação ao projeto parental e o contínuo engajamento no processo de parentalização, mutuamente desenvolvido por pais, mãe e filhos ao longo do tempo e dentro de um qualificado espaço de convívio. A adequada conformação da parentalidade socioafetiva reclama, pois, para além da configuração da posse do estado de filiação, que a experiência do "tornar-se pai" e "tornar-se mãe" seja assumida livremente e mediante a inequívoca exteriorização da vontade de ser investido neste particular status pessoal. O vínculo que daí sobressai reveste-se de uma natureza inegavelmente dialógica e relacional, aniquilando-se frente à coerção.

Num mundo "líquido" (BAUMAN, 2004) repleto de clivagens identitárias e crises de pertencimento, o que se pretende é que o Direito de Família, afastando-se dos mitos estigmatizantes e sua lógica desvirtuada, arrebanhe forças para responder com eficiência a pergunta aparentemente simples: “Quem é meu pai, quem é minha mãe?”. Que a solução para tal questionamento mire cada vez mais naqueles que desejam, amam e preparam sua prole para a vida, de modo que um dia esta mesma prole possa, munida destes referenciais, perpetuar através de um novo núcleo familiar essa carga histórica, social e cultural.

\section{REFERÊNCIAS}


ALMEIDA, Renata Barbosa de; RODRIGUES JÚNIOR, Walsir Edson. Direito Civil Famílias. Rio de Janeiro: Editora Lumen Juris, 2010.

AMARILLA, Silmara Domingues Araújo. O afeto como paradigma da parentalidade: os laços e os nós na constituição dos vínculos parentais. Curitiba: Juruá, 2014.

ARENDT, Hannah. Entre o passado e o futuro. Trad. Mauro W. Barbosa de Almeida. 2. ed. São Paulo: Perspectiva, 1979.

BAUMAN, Zygmunt. Amor Líquido: sore a fragilidade dos laços humanos. Trad. Carlos AlbertoMedeiros. Rio de Janeiro: Jorge Zahar, 2004.

BEVILÁQUA, Clóvis. Direito de família. Rio de Janeiro: Editora Rio, 1976.

BRASIL. Superior Tribunal de Justiça. Terceira Câmara Cível. Agravo Regimental em Recurso Especial n. ${ }^{\circ}$ 1.371.048/SP. Relator Ministro João Otávio Noronha. Brasília, DF, 06 ago.2015, DJe 12 ago.2015.

DIAS, Maria Berenice; PEREIRA, Rodrigo da Cunha (Coords.). Direito de Família e o novo Código Civil. Belo Horizonte: Del Rey, 2005.

GAMA, Guilherme Calmon Nogueira da. Princípios constitucionais de direito de família. São Paulo: Atlas, 2008.

GOMES, Orlando. Direito de família. 5. ed. Rio de Janeiro: Forense, 1983.

HOUZEL, Didier. As implicações da parentalidade. Trad. Alice Paes de Barros Arruda. In: SOLIS- PONTON, Letícia (Org.). Ser pai, ser mãe: parentalidade: um desafio para o terceiro milênio. Trad. Maria Cecília Pereira da Silva. São Paulo: Casa do Psicólogo, 2004.

KUHN, Thomas S. A estrutura das revoluções científicas. Trad. Beatriz Vianna Boeira e Nelson

Boeira. São Paulo: Perspectiva, 2009.

LEBOVICI, Serge. Diálogo Leticia Solis-Ponton e Serge Lebovici. In: SOLISPONTON, Letícia (Org.). Ser pai, ser mãe: parentalidade: um desafio para o terceiro milênio. Trad. Maria Cecília Pereira da Silva. São Paulo: Casa do Psicólogo, 2004a.

LÔBO, Paulo Luiz Netto. Direito ao estado de filiação e direito à origem genética: uma distinção necessária. In: PEREIRA, Rodrigo da Cunha (Coord.). Afeto, Ética, 
Família e o Novo Código Civil. Belo Horizonte: Del Rey, 2004.LÔBO, Paulo. Socioafetividade no direito de família: a persistente trajetória de um conceito fundamental. In: DIAS, Maria Berenice; BASTOS, Eliene Ferreira; MORAES, Naime Márcio Martins (Coords.). Afeto e Estruturas Familiares. Belo Horizonte: Del Rey, 2009.

PEREIRA, Rodrigo da Cunha. Direito de Família: uma abordagem psicanalítica. 3. ed. rev. atual., Belo Horizonte: Del Rey, 2003.

SOLIS-PONTON, Letícia. A construção da parentalidade. In: SOLIS-PONTON, Letícia (Org.). Ser pai, ser mãe: parentalidade: um desafio para o terceiro milênio. Trad. Maria Cecília Pereira da Silva. São Paulo: Casa do Psicólogo, 2004.

TEPDINO, Gustavo. Temas de direito civil. 4. ed. rev. atual. Rio de Janeiro:

Renovar, 2008. VILLELA, João Baptista. Repensando o direito de família. In:

PEREIRA, Rodrigo da Cunha (Coord.).

Anais do. I Congresso Brasileiro de Direito de Família - Repensando o Direito Horizonte: IBDFAM: OAB-MG, 1999.

VILLELA, João Baptista. O modelo constitucional da filiação: verdade e superstições. Revista

Brasileira de Direito de Família. Porto Alegre: Síntese, v.1, n. 2, pp. 138-139, jul/ago/set. 1999a.

VILLELA, João Baptista. Variações impopulares sobre a dignidade da pessoa humana. Superior

Tribunal de Justiça: Doutrina. Edição Comemorativa, 20 anos. Distrito Federal, p. 59-581, 2009. 